DOI: 10.20472/BMC.2018.008.012

ANDREA POTGIETER

University of Johannesburg , South Africa

KAGISO MABE

University of Johannesburg, South Africa

\title{
THE FUTURE OF ACCESSING OUR PAST: COLLABORATION AND DIGITISATION IN LIBRARIES, ARCHIVES AND MUSEUMS
}

\begin{abstract}
:
Technological innovation has led to disruptions in the global economy. In South Africa, one such disruption has been the shift towards the digitisation of resources that were previously only available in hard copy. Institutions most notably affected by the digitisation drive, have been libraries, archives, and museums (LAMs), which serve as important cultural heritage organizations. Considering the significant financial implications of a digitisation project, this paper explores the possible benefits and challenges that are faced when LAMs collaborate with each other, when digitising content. This qualitative, cross sectional study compared results from the data of 21 interview transcripts, which were first analysed through thematic coding in ATLAS.ti, and then analysed in Leximancer, a software tool which applies natural language processing to text. The results discuss relevant themes and concepts, revealed during the interviews with digitising-focused employees, at various LAMs in South Africa. This paper aimed to illuminate which user-generated perceptions of concerns and opportunities should be noted when an organization considers a collaborative technological intervention, specifically in the context of LAMs in South Africa. Findings showed that the sharing of technology, skills and knowledge was prevalent when considering potential benefits of a collaborative digitisation project, while access to resources and the inefficient use of resources, were identified as significant challenges in collaborative digitisation projects. The novelty of this discussion lies within the triangulation of results by using different analysis tools, and the value of the research is the unique view given of the challenges and opportunities which arise when a collaborative digitisation project is deployed.
\end{abstract}

\section{Keywords:}

Knowledge management, Knowledge sharing; Libraries, archives \& museums, digitisation, collaboration, South Africa

JEL Classification: D83, L31, D80 


\section{Introduction}

Organisations are faced with the complicated task of implementing the use of innovative technologies, while being constrained by practical limitations regarding funding, infrastructure and human capital (Clough, 2013:2). Terras (2011:16) highlights a shift to large scale digitisation efforts, as well as "the growth in use and user expectations regarding the provision and quality of digitised material." By collaborating, specifically on the technology-reliant task of digitisation, libraries, archives and museums (LAMs) in South Africa could potentially overcome the mentioned constraints (Daly, Jones, Shipp, Matuzelis, O'Connor, 2015:2).

This paper reports on a segment of the data gathered for an MPhil degree in Information Management, which was conferred in June 2018 (Mabe, 2017). This paper therefore only focuses on selected benefits and foreseeable challenges if LAMs in South Africa were to pool resources towards digitisation ventures. The authors report on interviews conducted with 21 employees at selected LAMs in the Gauteng province of South Africa, by discussing the data as analysed using ATLAS.ti, as well as using Leximancer, a text analysis tool that measures the co-occurrence of concepts and the relationship between concepts within a body of text (Leximancer, 2018:8). As is required, the authors will firstly present the theoretical framework within which the study was conducted.

\section{Digitisation, collaboration and LAMs}

The grouping of LAMs ${ }^{1}$ became academically relevant with the rise of the digital era to "find points of commonality among various cultural heritage institutions" (Davis \& Howard, 2013:15). A practical example of a convergence of traditionally "divergent and unique" institutions, is the Google Cultural Institute, which allows users to "discover artworks, collections and stories from all around the world in a new way" (Askin, 2015:1; https://www.google.com/culturalinstitute/about/). This project invites cultural institutions to leverage its digitisation technologies to "bring the world's cultural heritage online."

Chitambo, Mabe and Potgieter (2016:178) state that, for a contemporary heritage institution "to [remain] relevant in the technological age", it is vital to incorporate digitisation into its strategic objectives. According to Coutts (2017:1), digitisation gained popularity in heritage sectors in the early 2000 s, as a way to revolutionise "access to all forms of information and artefacts." Digitisation refers to the transformation of analogue

\footnotetext{
${ }^{1}$ LAM refers to Libraries, Archives and Museums. The closely related acronym GLAM includes the term "galleries" in the classification. As Davis and Howard (2013:16) state, in North America "art museums" are considered incorporated under "museums", as an "art gallery" is considered a place from which to buy artwork; this form of classification applies to this paper as well.
} 
information into a digital format (Sotirova, Peneva, Ivanov, Doneva \& Dobreva, 2013:26). Heritage organisations, such as LAMs, typically undertake digitisation efforts to protect societal culture for succeeding generations and to make collections more widely available (Peters, Marinova, van Faassen \& Stasiuk, 2017:114); these efforts are informed by policies on the matter of digitisation (Çakmak \& Yılmaz, 2012:151). Many LAM institutions, especially those supported by public funding, are mandated to deliver predetermined outcomes within these policy frameworks, however there is a prevalence of discord between policy and practice "for many institutions engaged with information" (Batt, 2016:27). The research presented in this paper could potentially inform future policies relating to digitisation efforts within LAMs, since a holistic approach to this issue has been highlighted for future consideration of research efforts (Beyene, 2016:13).

Despite the necessity of digitising content, LAMs are faced with many obstacles in attempting to execute successful digitisation efforts. Digitisation is complicated process that requires librarians to excel at their traditional role, as well as at technical tasks such as web design and graphics editing (Zaid \& Olatokunbo, 2015:104). The complexity of digitisation has become evident, and is also highlighted by Terras (2011:7) as the author discusses the rise of the digitising culture within digital libraries:

"It took a while for institutions to realise that digiti[s]ation is a costly and time consuming exercise, which will not reap financial rewards but provides benefits for users, expanding skills, expertise and services, whilst requiring ongoing maintenance, development, and funding. "

Digitisation in silos undermines the "value and impact" of heritage organisations' attempts to preserve collections and make information more widely accessible, where collaboration (Coutts, 2017:117). Collaboration between LAMs could possibly alleviate some of the financial and human capital challenges that digitisation demands, as employees could not only share skills and knowledge, but institutions could pool resources such as infrastructure and software (Cathro, 2010). Zaid and Olatokunbo (2015:105) concurs with the notion and classifies collaboration between institutions "in the digital world" as "necessary, desirable, inevitable, and a key initiative" to strategic management.

Collaboration refers to the concept of distinctive factions cooperating and sharing proficiencies, to accomplish a common goal (Australian Research Alliance for Children and Youth (ARACY), 2013:1). These factions could imply intra-organisational cooperation, or inter-organisational cooperation (Wirsich, Kock, Strumann \& Schultz, 2016:708). There are several benefits to collaborating in digitisation efforts, such as: a broadening of access to information, the improved public perception of the value of LAMs, pooling of scarce resources, and the promotion of proven practices between the collaborators, skill sharing and a broadening of knowledge, and the sharing of the financial burden presented by the acquisition of software and training (Mabe, 2017:9). 
In developing countries, such as South Africa, LAM employees' stance on digitisation can mean the difference between a successful endeavour and a failure (Boamah, 2017:65). These attitudes can further derail any collaboration attempts among LAMs, where the end goal is to preserve culture and to create a common heritage (Terras, 2011:16). Therefore, determining the perceptions of LAM employees in South African LAMs is a vital component of introducing new, or improving upon existing, collaborative digitisation efforts. This paper focuses on the concerns of LAM employees around digitisation and collaboration, and highlights benefits identified by these employees, when these undertakings were discussed.

\section{Research design and methodology}

The following discussion clarifies the design and execution of the research project.

\subsection{Research design}

The researchers adopted an interpretivist approach, as a specific phenomenon was being investigated (Biedenbach \& Müller, 2011:86). The chosen research paradigm was a mono-method qualitative approach, as this is associated with interpretivism, since meaning is constructed subjectively (Ang, 2014:53). This subjectivity was somewhat diminished by the analysis of the same data set through two different analysis tools.

Saunders, Lewis, \& Thornhill (2012:48) note that an inductive research approach, such as that applied to this study, allows themes to emerge from the data and furthermore aims at observing the occurrence which is under investigation, within its context. It is also with this consideration for context that case study research was chosen as a research strategy. Since multiple cases were explored in this study, the related but distinctive context of sixteen different LAMs could be considered (Gustafsson, 2017).

\subsection{Research methodology}

Purposive sampling was employed for the purposes of this study. As a non-probability sampling technique, this method was used to strategically select interviewees from whom to gather data for this study (Bryman \& Bell, 2011:319). Purposive sampling - or judgemental sampling - allows a researcher to select interviewees that are most suitable to answer the research questions that have been identified (Saunders et al., 2012287). As is shown in Table 1 below, the sample size for this study was 21 interviewees, within 16 different LAMs located across the Gauteng province of South Africa. LAM employees who bore knowledge on digitisation and collaboration were sought to participate in the study. 
Table 1: Institutional participation and number of participants

\begin{tabular}{|l|c|c|}
\hline Institution Code & Type & Number of Participants \\
\hline Brenthurst & Library & 2 \\
\hline Freedom & Archive & 1 \\
\hline Art gallery & Museum & 2 \\
\hline Gay & Archive & 2 \\
\hline UP & Library & 1 \\
\hline Wits & Library & 1 \\
\hline Ditsong & Museum & 1 \\
\hline Rock & Archive & 1 \\
\hline Papers & Archive & 1 \\
\hline Mandela & Archive & 1 \\
\hline Boksburg & Library & 1 \\
\hline Randwest & Library & 1 \\
\hline Holocaust & Museum & 2 \\
\hline National & Archive & 1 \\
\hline Joburg & Library & 1 \\
\hline Africa & Museum & 2 \\
\hline
\end{tabular}

The data collection tool used in this study was a non-standardised, semi-structured interview schedule, with questions that were created to intentionally spark an explorative discussion between the interviewees and the interviewer (Qu \& Dumay, 2011:246).

Data analysis for this research was done using the Computer Assisted Qualitative Data Analysis (CAQDAS) tool ATLAS.ti. The interviews were recorded and transcribed and analysed within ATLAS.ti, using a thematic coding process. Friese (2014:1) makes it clear that CAQDAS does not analyse data for the researcher, but rather assist the researcher in the process of data analysis.

For this paper, a section of the data used in the original study was also analysed using Leximancer, a natural language processing tool. Leximancer analyses textual documentation and displays "the conceptual structure of text" by quantifying the relationships between themes (Leximancer, 2018:3). The data analysed using this tool was discussed in the findings of this paper, and related to those findings discovered using ATLAS.ti and thematic analysis.

\section{Discussion of findings}

As mentioned, there is a consensus that collaboration has the potential to aid LAMs in their efforts to digitise heritage artefacts, and it is with this topic that the interview with the study participants commenced. The discussion ultimately focused on selected potential benefits to digitisation efforts, and also challenges that could be faced, should collaboration be pursued (Mabe, 2017:59). 


\subsection{Benefit: Collaboration and cost saving}

All interviewees agreed that collaboration would be a cost saving initiative, for digitisation efforts (Mabe, 2017:59). This is not an uncommon assertion, as the cost-saving potential of collaboration efforts relating to digitisation is well established (Duff, Carter, Cherry, MacNeil \& Howarth, 2013:4; Robinson, 2012:413; Blackmore, Meklenburg \& Kaplan, $2011: 1618)$. Innovation is cited as the concept that allows collaborating LAMs to lessen the financial implications of undertaking digitisation efforts on their own (Mabe, 2017:58).

An example of cost saving through collaboration was given by two interviewees associated with the National Department of Arts and Culture. Per these interviewees, their division could halt their current outsourcing of digitising efforts, and rather turn to collaboration with suitable LAMs who were also "probably" outsourcing this service. These interviewees noted that this could not only save money, but would also ensure the digitising skills would "remain in-house" (Mabe, 2017:58).

The matter of what to do with the funds that would be saved by collaborating instead of outsourcing, was raised by three interviewees. It was suggested that any funding made available by a reduction in outsourcing costs, could be applied to other areas such as "more competitive salaries." Another interviewee suggested that, in their municipality, all the museums could collectively hire an official photographer, as opposed to each museum hiring its own photographer (Mabe, 2017:59). Internationally, the strategy of collaboration to divide high costs is fast becoming a trend among heritage organisations, since this manner of operation also divides the risks associated with costly investments, and should translate to costly human capital (Robinson, 2015:12).

\subsection{Benefit: Collaborating through skill sharing}

One interviewee spoke specifically on the topic of cost saving by collaborating with another institution on the sharing of skills. The interviewee's institution "invit[ed] an individual from another institution to share skills" with employees "who found it difficult to operate a newly imported digitising machine" (Mabe, 2017:59). In this scenario, described by the interviewee, their organisation did not have to send employees on expensive training courses, as they could have an interactive conversation with someone who not only held the right knowledge, but also held context of the environment in which the knowledge would be utilised. Ten more interviewees asserted their optimist about collaboration in terms of skill sharing, as it was a "free option for receiving further training" (Mabe, 2017:59).

Allen and Bishoff (2015:47) support the notion of skill sharing through collaboration, and acknowledge the potential for significant saving of cost. Mabe (2017:60) is clear, however, that employees should not only receive informal skills sharing as a training 
initiative. It is suggested that skill sharing in this manner should be utilised "if skills that are needed can be found in a LAM's knowledge network" (Mabe, 2017:60).

The existence of a digitising backlog was raised by three different interviewees, who stated that this dilemma "was a challenge to overcome" (Mabe, 2017:60). The adage of "time is money" was mentioned by two interviewees, and yet another interviewee stated that learning from another organisation's mistakes could also save time and that "this can be made possible through collaboration" (Mabe, 2017:60). The same interviewee was also of the opinion that collaboration would contribute to less time wasted as employees currently spent hours trying to train themselves in digitising tools, where they could be able to ask someone for help, if their organisation had collaboration channels in place (Mabe, 2017:60).

\subsection{Benefit: Sharing technology through collaboration}

Apart from presenting cost benefits, collaboration between LAMs is deemed a necessity to sharing technology infrastructure as well (Allen \& Bishoff, 2017:47). Eight interviewees noted that a combined digitisation effort makes more strategic sense, as it was not viable for every LAM in a municipality or district to purchase an expensive piece of machinery that will only be used for a limited time.

As an example of effective collaboration in terms of sharing technology, an interviewee mentioned the sharing of a knowledge management system by libraries on the East Rand of Johannesburg. This interviewee attributed these institutions' time and cost saving results to the sharing of content on the knowledge management system (Mabe, 2017:60). Three interviewees further supported the concept of collaboration in sharing content platforms such as this, concurring with Olson (2008:212) that the sharing of platforms has the potential to mitigate cost.

Online storage fees were another concern which an interviewee mentioned as a possible benefit to collaboration. If no collaboration were to take place, each LAM would be responsible for paying a subscription fee to host their digital content online (Mabe, 2017:60). However, should LAMs collaborate through their skills and technology, it stands to reason that they could also collaborate on storage fees. Not only would this save money, but each institution's users would have access to all the content that the parties collaborated on. Furthermore, the administration of websites serving as the interface between the digitised database and the end user, is also an expensive venture per another interviewee (Mabe, 2017:60). Verheusen (2008:32) warns that storage costs and website maintenance will continue to rise, however through collaboration some of the cost may be absorbed collectively. 


\subsection{Challenge: Time constraints}

Most interviewees cited time constraints as a contributing factor in not collaborating with other LAMs. The problem seemed to be that the opportunity to collaborate rarely presenting itself, since the pressure to meet day-to-day obligations was greater than the need to collaborate, despite employees' willingness to do so. To illustrate their point, one interviewee bemoaned that they did not have "time to look up and think about alternative options to getting work done" (Mabe, 2017:76).

Four of the interviewees stated that they hold the belief that digitisation is a time-intensive endeavour, and that "you cannot rush it, it never gets less, only becomes more, and does not have an end" (Mabe, 2017:76). Shampa and Sashi (2014:223) unfortunately support this notion, by confirming that digitisation is not only labour intensive, but places considerable pressure on employees in terms of time.

Ocholla (2008:469) states that collaboration is most often hindered by a lack of dedicated time. Interviewees explained that the digitisation effort which they were familiar with, was run with a specific timeframe in mind. That timeframe did not accommodate additional activities such as collaboration, and only took the task of digitising into consideration. According to these interviewees, collaboration is seen as a separate task, not as an enable towards reaching the digitising goal (Mabe, 2017:76). As an interviewee explained: "the bigger issue of these deadlines is that people end up looking to their performance, which prevents them from looking around to see where they can collaborate" (Mabe, 2017:76).

\subsection{Challenge: Lack of management buy-in}

Fitsommons (2009:22) states that employees should realise that the most effective way to get buy-in for collaboration efforts from management, is to link such an initiative to a business objective. This does not seem to have been achieved by employees at the LAMs relevant to the interviewees, as one stated that collaboration is often seen as a non-essential activity - an activity not related to their core business. Another interviewee brought up the time-intensive bureaucracy associated with simply attending a seminar or conference (Mabe, 2017:81). It is clear from these assertions that collaborative activities - even informal events such as conference attendance - are not seen as crucial to business.

If management does not get on board with collaboration efforts, these endeavours will not form part of the institution's strategic objectives. This implies that it will not receive funding or the attention needed for success Mallon (2017:228). However, buy-in from management is not the only deciding factor in the success rate of a collaboration effort. As one interviewee noted, their institution's IT department - which serves the entire institution - does not support their digitisation efforts (Mabe, 2017:81). For a technology- 
dependent function such as digitising to not be supported by an essential function such as IT, could be detrimental, as it is crucial to the success of a digitisation project to have buy-in and collaboration from all stakeholders related to the project (Schlak, 2015:398). Another interviewee was convinced that, had they not managed to get buy-in from their director and board of trustees, they would not have been in the partnership they are currently in.

Schlak (2015:398) simplifies the concept of buy-in by stating that it implies that the project has been given the "go-ahead" (Schlak, 2015:398). One interviewee provided an example where the go-ahead was not given by management, and where this oversight lead to the failure of the relevant institution and a local college (Mabe, 2017:81). Yet another interviewee voiced their annoyance at the bureaucracy by stating "you will not get a buy-in from those higher up in the hierarchy, but they always come running to you when there is a problem" (Mabe, 2017:82).

\subsection{Challenge: Personality traits and organisational culture}

Four interviewees expressed their view that individuals' own agendas, or those of organisations, could prevent collaboration from taking place. Ocholla (2008:469) explains that institutions' exclusiveness impedes collaborations from taking place, which could result from individuals becoming complacent in the way their organisation operates and not wanting to venture out of that comfort zone. Another interviewee said that certain internal priorities and processes within institutions hindered them from looking outward and collaborating.

Ocholla (2008:469) warns of complacency among LAM employees, specifically if these employees become stagnant in their way of doing things. A culture that promotes exclusivity and pits employees against each other will certainly prevent a collaborative philosophy to reign supreme. Four interviewees touched on this subject by noting that they have experienced the thwarting of collaboration through others' personal agendas within LAMs. Furthermore, an interviewee stated that "certain internal priorities and processes within institutions" dissuaded employees from seeking to collaborate with external partners (Mabe, 2017:82).

Differences in personality was identified as a hindrance to collaboration by seven interviewees, as "some people just do not want to share" (Mabe, 2017:82). Two of these interviewees elaborated by stating that, in addition to personality traits, the organisation culture within a LAM could also prevent collaboration from taking place. Ocholla (2008:469) echoes the sentiment that it is simply not in the nature of certain individuals to share skills and knowledge, and that this combined with a sub-optimal organisational culture, will surely hinder collaboration. 
The issue of generational differences was raised by one interviewee. At this interviewee's institution, the staff component mainly consists of two generations. The interviewee explained that the "older" generation were trained as traditional librarians, and were taught to protect and preserve information. The "younger" generation was trained in the information sciences and are of the school of thought that promotes the accessibility and sharing of information (Mabe, 2017:83). These disparities in philosophy is a great source of conflict within this institution and inhibits any collaboration between these disagreeing colleagues. Van der Walt and Du Plessis (2010:1) cites generational diversity as the element at play here, and note that different generations perceive the world and by extension the concept of collaboration, differently.

The concept of introversion was mentioned by two interviewees, who stated that traditional librarians tend to be introverted, and prefer working in silos and do not appreciate interacting with others. Since librarians do score low on vivacity, indicating a predilection for introversion, it stands to reason that this observation is not unfounded (Williamson \& Lounsbury, 2016:135). The interviewees that raised this point agreed that, when one considers the context that contemporary libraries find themselves in, that "this was a mind-set that they need to get out of" (Mabe, 2017:83).

Sadly, one interviewee believed that people were inherently self-centred and that a desire to remain competitive prevents employees from collaborating with each other. Suppiah and Sandhu (2011:465) do agree that employees may be more likely to withhold knowledge they deem competitive, but the authors places the responsibility on the organisation to create a culture that provides more incentive to share and collaborate, than it does to individual success. Another interviewee mentioned the possibility that pride could prevent a person from asking for help, however, Al-Alawi, Al-Marzooqi and Mohammed (2007:24) again bring focus to the organisational culture, which should support knowledge sharing, encouraging employees to converse and collaborate.

\subsection{Leximancer findings}

Figure 1 shows the concept map generated by Leximancer, based on the interview questions relevant to this paper. Those questions focused on the benefits and challenges discussed above. The map in Figure 1 shows the concepts in grey nodes, and it also illustrates the relationships between concepts. These concepts are grouped into themes, based on their proximity to one another. The themes are shown by coloured circles. 
Figure 1: Leximancer concept map, based on the aggregated interview data

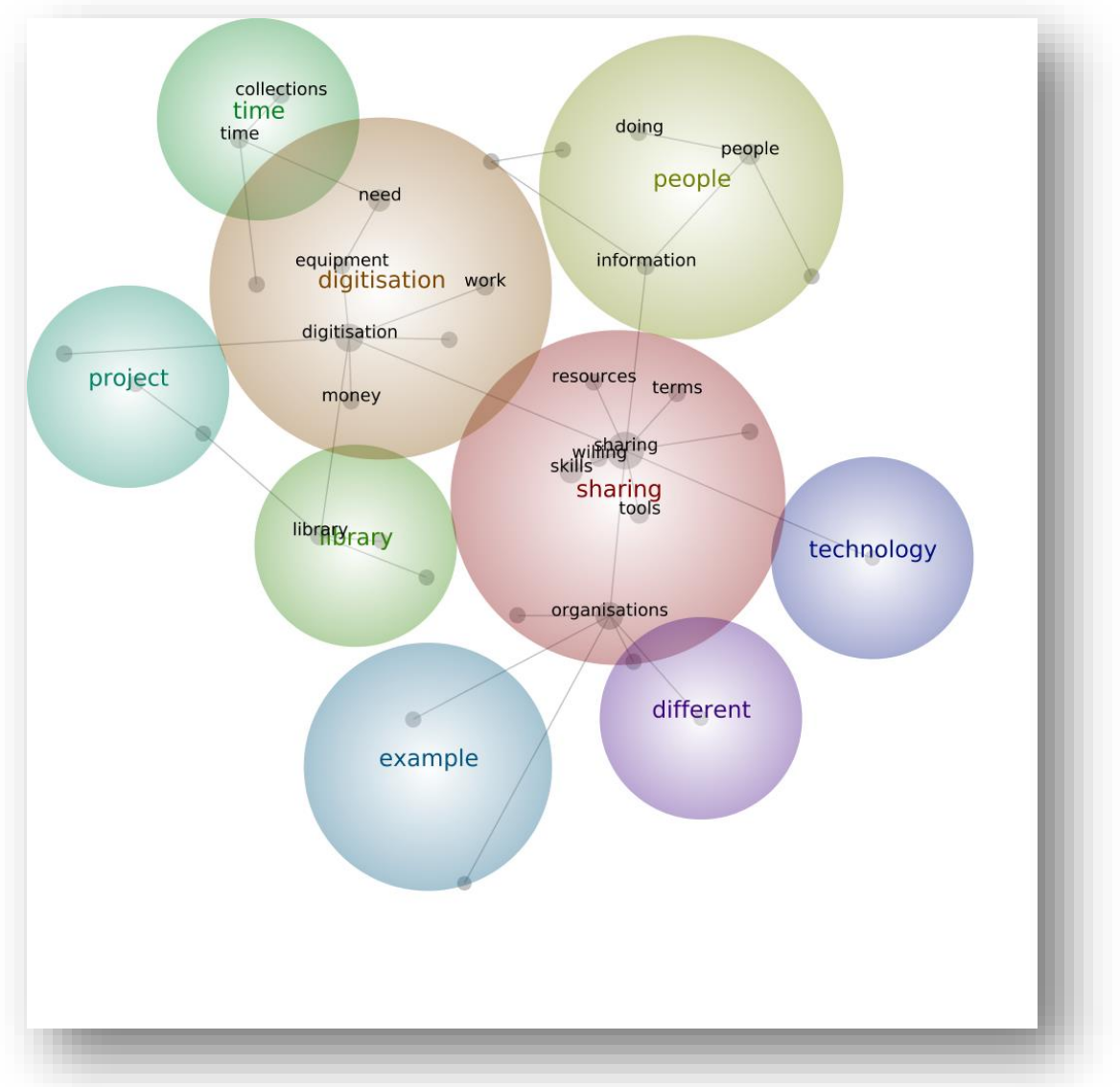

"Sharing", per the Leximancer analysis, was the most prominent theme arising from the interview data. When the concepts related to "sharing" are examined, the most frequent associations were made to "tools", "skills", "knowledge", and "resources." In the ATLAS.ti analysis, skill sharing was also identified as a benefit to collaboration. The concept of resources being "shared" confirms the initial analysis that collaboration could support cost saving, and the frequency of the concept "tools" repeats the finding that the sharing of technology could be achieved through collaboration. Since the focus of the research had been on collaboration, the prominence of "sharing" is reassuring regarding the reliance of the initial findings. Collaboration would require the sharing of several resources, ranging from monetary, to human, and even time.

Apart from digitisation being a prominent theme, as is to be expected considering the focus of the research, "people" was identified as the third most noticeable theme within the interview data. When the concepts related to "people" is mined, the most frequently related word is shown to be "problem", as can be seen in Figure 2 below. Considering the ATLAS.ti analysis indicated personality traits and culture as challenges facing collaboration on digitising, the prevalence of this theme does not come as a surprise. 
Figure 2: Leximancer analysis - concept-related words of the theme "people"

\begin{tabular}{|c|c|c|c|c|}
\hline \multicolumn{3}{|c|}{ Selected Concept: people (144) } & \multirow{2}{*}{$\begin{array}{r}\text { Ranked View } \\
\text { Likelihood }\end{array}$} & \multirow[t]{2}{*}{ Export } \\
\hline Related Name-Like & & Count & & \\
\hline Related Word-Like & \multicolumn{2}{|c|}{ Count Likelihood } & & \\
\hline Q problem & 9 & $22 \%$ & & \\
\hline$Q$ doing & 8 & $11 \%$ & & \\
\hline Q technology & 4 & $10 \%$ & & \\
\hline Q information & 6 & $09 \%$ & & \\
\hline Q willing & 3 & $09 \%$ & & \\
\hline$Q$ able & 3 & $08 \%$ & & \\
\hline Q time & 7 & $07 \%$ & 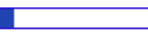 & \\
\hline$Q$ need & 8 & $06 \%$ & 工 & $\square$ \\
\hline Q skills & 5 & $06 \%$ & 工 & \\
\hline
\end{tabular}

On the concept map, "time" is shown as the next most prominent theme within the data. The thesaurus terms related to the concept of "time", highlight the challenges identified within the ATLAS.ti analysis. The terms "effort", "schedule", "luxury" and "wasting" point to a nuance of frustration around the concept of "time." This sentiment was discussed as a challenge to collaboration in digitising efforts, with several interviewees mentioning that time was not a resource that was readily made available for collaboration efforts.

A concept not identified by Leximancer, but highlighted in the initial ATLAS.ti results, was that of management buy-in. Although this concept was discussed by interviewees, the Leximancer analysis showed no prominence of the frequency with which this concept was mentioned. However, the literature cited in the discussion of buy-in, does support the notion that it is a vital consideration when planning a collaborative digitising effort. For the purpose of this paper, on this particular point, the Leximancer results did not reflect the results produced through the ATLAS.ti analysis.

\section{Conclusion}

The digital era has given rise to the need for LAMs to digitise heritage information. Users are accustomed to executing daily tasks in a digital arena, and expect this to be provided in all matters concerning access to information. Digitisation is a complex undertaking which involves a lot of manpower, and financial resources. A possible solution to the burden that LAMs face when considering digitising efforts, is to collaborate with each other in terms of funding, skills and technology.

This research found that cost saving, skill sharing and the sharing of technological tools were some of the benefits that LAM employees perceive to gain from collaboration efforts relating to digitising. Two of the challenges identified, that of time constraint and personality traits - which also relates to organisation culture - were found to be 
prominent issues deterring collaboration for digitising. Gaining management buy-in for collaboration efforts was initially found to be a challenge, and was supported by literature. However, the Leximancer analysis did not flag this issue as prominent.

\section{References}

AL-ALAWI, A.I., AL-MARZOOQI, N.Y. and MOHAMMED, Y.F. (2007) Organizational culture and knowledge sharing: Critical success factors. Journal of Knowledge Management, Vol. 11, No. 2, pp. 22-42.

ALLEN, N. and BISHOFF, L. (2015) Collaborative digitization: Libraries and museums working together. Advances in Librarianship, Vol. 26, pp. 43-81.

ANG, S.H., (2014) Research design for business \& management. Sage.

ARACY (2013) What is collaboration? Available from:

http://www.aracy.org.au/publications-resources/

ASKIN, N. (2015) Collaboration and crowdsourcing: the future of LAM convergence. See Also: The UBC School of Library, Archival and Information Studies Student Journal, Vol. 1, No. 1, pp 1-15. Available from: http://ojs.library.ubc.ca/index.php/seealso/article/view/186336

BATT, C. (2015) Digital information strategies: From applications and content to libraries and people. Elsevier Ltd.

BEYENE, W.M. (September 2016) Realizing inclusive digital library environments: opportunities and challenges. In International Conference on Theory and Practice of Digital Libraries, pp. 3-14. Switzerland, Cham: Springer.

BLACKMORE, C.C., MEKLENBURG, R.S. and KAPLAN, G.S. (2011) At Virginia Mason, collaboration among providers, employers, and health plans to transform care cut costs and improved quality. Health Affairs, Vol. 30, No. 9, pp. 1680-1687.

BOAMAH, E. and LIEW, C.L. (November 2017) Conceptualising the digitisation and preservation of indigenous knowledge: The importance of attitudes. In International Conference on Asian Digital Libraries, pp. 65-80. Switzerland, Cham: Springer.

ÇAKMAK, T. and YILMAZ, B. (September 2012) Overview of the Digitization Policies in Cultural Memory Institutions in Turkey. In International Symposium on Information Management in a Changing World, pp. 150-163. Berlin, Heidelberg: Springer-Verlag.

CATHRO, W. (2010) Collaboration across the collecting sectors. National Library of Australia Staff Papers. Available from: https://www.nla.gov.au/content/collaboration-across-the-collecting-sectors

CHITAMBO, I., MABE, K. and POTGIETER, A. (September 2016) The Role of Digitisation in Knowledge and Content Management. In European Conference on Knowledge Management, pp. 174-180. Academic Conferences International Limited.

CLOUGH, G.W. (2013) Best of both worlds: Museums, libraries, and archives in a digital age. Washington DC: Smithsonian Institution. 
COUTTS, M. (2016) Stepping Away from the Silos: Strategic Collaboration in Digitisation. Chandos Publishing.

DALY, R., JONES, S., SHIPP, J., MATUSELIS, L. and O'CONNOR, M. (2015) Rediscovering historic Wollongong-a community and educational collaboration project. ALIA Information Online 2015: at the edge, ALIA, pp. 1-10. Available from:

\section{http://ro.uow.edu.au/cgi/viewcontent.cgi?article=1499\&context=asdpapers}

DAVIS, W. and HOWARD, K. (2013) Cultural policy and Australia's national cultural heritage: issues and challenges in the GLAM landscape. The Australian Library Journal, Vol. 62, No. 1, pp.15-26.

DUFF, W.M., CARTER, J., CHERRY, J.M., MACNEIL, H., and HOWARTH, L.C. (2013) From coexistence to convergence: Studying partnerships and collaboration among libraries, archives and museums. Information Research, Vol. 18, No. 3, pp. 1-26.

FITSIMMONS, G. (2009) Resource management: People gaining buy-in. The Bottom Line, Vol. 22, No. 1, pp. 21-23.

FRIESE, S. (2014) Qualitative data analysis with ATLAS.ti. London: Sage Publications.

GUSTAFSSON, J. (2017) Single case studies vs. multiple case studies: A comparative study. Available from: www.diva-portal.org

LEXIMANCER (2018) Leximancer User Guide Release 4.5. Available from:

https://doc.leximancer.com/doc/LeximancerManual.pdf

MABE, K. (2017) Collaboration between libraries, archives and museums (LAMS) in the digitisation of information in South Africa (Masters dissertation). Auckland Park, Johannesburg: University of Johannesburg. Available from: http://hdl.handle.net/10210/271860

OCHOLLA, D.N. (2008) The current status and challenges of collaboration in library and information studies (LIS) education and training in Africa. New Library World, Vol. 109, No. 9/10, pp. 466-479.

OLSON, E.L. (2008) The implications of platform sharing on brand value. Journal of Product \& Brand Management, Vol. 17, No. 4: 244-253.

PETERS, N., MARINOVA, D., van FAASSEN, M. and STASIUK, G. (2017) Digital preservation of cultural heritage. In Technology, Society and Sustainability, pp. 107-114. Switzerland, Cham: Springer.

QU, S. Q and DUMAY, J. (2011) The qualitative research interview. Qualitative Research in Accounting and Management, Vol. 8, No. 3, pp. 238-264.

ROBINSON, H. (2015) Knowledge utopias: An epistemological perspective on the convergence of museums, libraries and archives. Sydney: University of Sydney.

SAUNDERS, M., LEWIS, P., and THORNHILL, A (2012) Research methods for business students. $6^{\text {th }}$ edition. Essex: Pearson.

SCHLAK, T.M. (2015). Social capital and leadership in academic libraries: The broader exchange around "Buy In". Library Management, Vol. 36, No. 6/7, pp. 394-407. 
SHAMPA P. and SASHI P.S. (2014). Digitization initiatives and special libraries in India. The Electronic Library, Vol. 32, No. 2, pp. 221-238.

SOTIROVA, K., PENEVA, J., IVANOV, S., DONEVA, R. and DOBREVA, M. (2013) Digitization of cultural heritage - standards, institutions, initiatives. Available from:

$\underline{\text { www.math.bas.bg/infres/book-ADCH/ADCH-ch1.pdf }}$

SUPPIAH, V. and SANDHU, M.S. (2011) Organisational culture's influence on tacit knowledge-sharing behaviour. Journal of Knowledge Management, Vol.15, No. 3, pp. 462-477.

TERRAS, M.M. (2011) The Rise of Digitization. In Digitisation Perspectives, pp. 3-20. Sense Publishers.

VAN DER WALT, S. and DU PLESSIS, T. (2010) Leveraging multi-generational workforce values in interactive information societies. South African Journal of Information Management, Vol. 12, No. 1, pp. 1-7.

VERHEUSEN, A. (2008) Mass digitisation by libraries: Issues concerning organisation, quality and efficiency. Liber Quarterly, Vol.18, No. 1, pp. 28-38.

WILLIAMSON, J.M. and LOUNSBURY, J.W. (2016) Distinctive 16 PF personality traits of librarians. Journal of Library Administration, Vol. 56, No. 2, pp. 124-143.

WIRSICH, A., KOCK, A., STRUMANN, C and SCHULTZ, C. (2016) Effects of University-Industry Collaboration on Technological Newness of Firms. Journal of Product Innovation Management, Vol. 33, No. 6, pp 708-725. 